\title{
Increased Anxiety and Depression in Danish Cardiac Patients with a Type D personality: Cross-Validation of the Type D Scale (DS14)
}

\author{
Helle Spindler • Charlotte Kruse • Ann-Dorthe Zwisler • \\ Susanne S. Pedersen
}

Published online: 26 March 2009

(C) The Author(s) 2009. This article is published with open access at Springerlink.com

\begin{abstract}
Background Type D personality is an emerging risk factor in cardiovascular disease. We examined the psychometric properties of the Danish version of the Type D Scale (DS14) and the impact of Type D on anxiety and depression in cardiac patients.

Method Cardiac patients $(n=707)$ completed the DS14, the Hospital Anxiety and Depression Scale, and the Eysenck Personality Questionnaire. A subgroup $(n=318)$ also completed the DS14 at 3 or 12 weeks.

Results The two-factor structure of the DS14 was confirmed; the subscales negative affectivity and social inhibition were shown to be valid, internally consistent (Cronbach's $\alpha=0.87 / 0.91$; mean inter-item correlations $=$ $0.49 / 0.59)$, and stable over 3 and 12 weeks $(r=0.85 / 0.78$; $0.83 / 0.79 ; p \mathrm{~s}<0.01)$. Type $\mathrm{D}$ was an independent associate of anxiety $(\beta, 0.49 ; p<0.01)$ and depression $(\beta, 0.47 ; p<$ $0.01)$ in univariable linear regression analysis and remained a significant independent associate of anxiety $(\beta, 0.26 ; p<$
\end{abstract}

H. Spindler

Department of Psychology, Aarhus University,

Aarhus, Denmark

C. Kruse

Department of Cardiology, Holbæk Hospital,

Holbæk, Denmark

A.-D. Zwisler

National Institute of Public Health,

Copenhagen, Denmark

S. S. Pedersen $(\bowtie)$

CoRPS, Department of Medical Psychology, Tilburg University,

Room P506, Warandelaan 2, PO Box 90153, 5000 LE Tilburg,

The Netherlands

e-mail: s.s.pedersen@uvt.nl
$0.01)$ and depression $(\beta, 0.17 ; p<0.01)$ in adjusted analyses.

Conclusions The Danish DS14 was shown to be a valid and reliable measure associated with increased symptoms of anxiety and depression independent of sociodemographic and clinical risk factors. The DS14 may be used in research and clinical practice to identify high-risk patients.

Keywords Anxiety - Coronary artery disease - Depression . DS14 · Type D personality · Validity

\section{Introduction}

Psychological risk factors have been implicated in the onset and progression of cardiovascular disease (CVD) [1-3] and associated with impaired health status $[2,4,5]$. The first psychological factor to gain risk factor status was the Type A Behavior Pattern (TABP), characterized by time urgency, hostility, and impatience [6]. However, later inconsistent results in relation to TABP led psychosomatic research to shift focus from personality factors towards mood and affective disorders [7]. In this context, depression is the mood state that has received the most attention. Generally, depression has been associated with a 2- to 4fold risk of mortality [8], an increased risk of impaired health status [5, 9-11], noncompliance [12, 13], and healthcare consumption $[14,15]$, although a recent meta-analysis questions the status of depression as an independent risk factor in CVD [16].

Currently, there is a resurgence of interest in more chronic psychological factors, such as personality, in the context of CVD [9, 10, 17, 18]. A personality approach may have advantages over a mood state approach, as 
personality is less likely to be influenced by acute events, such as acute myocardial infarction (AMI), and to be confounded by somatic health, including disease severity $[19,20]$. The distressed (Type D) personality is an emerging risk factor in CVD that has been associated with adverse prognosis, impaired health status, and a wide range of emotional distress, such as anxiety and depression [2]. The Type D construct was developed in patients with ischemic heart disease, but as shown in a recent review, the construct has value across CVD patient groups, including peripheral arterial disease, chronic heart failure (CHF), arrhythmia, and in patients treated with revascularization procedures [2].

Patients with a Type D personality are characterized by high scores on the two stable personality traits, negative affectivity and social inhibition [21]. These patients have a gloomy outlook on life, tend to feel sad, and experience increased negative emotions (i.e., high negative affectivity), while not sharing these emotions with others due to fears of how others may react (i.e., high social inhibition). It is important to emphasize that it is the co-occurrence of a high score on both traits that incurs an increased risk of adverse health outcomes, with recent studies showing that social inhibition moderates the effect of negative affectivity on prognosis [17, 22]. In addition, the impact of Type $\mathrm{D}$ personality on prognosis is independent of mood states, such as anxiety and depression $[17,23]$ and is not confounded by somatic health, including disease severity $[19,20]$. Type D also distinguishes itself from depression and other mood states in that Type D represents a normal personality construct and is a chronic risk factor ( $\geq 2$ years), whereas depression is a measure of psychopathology and comprises an episodic risk factor $(<2$ years $)$ [2].

Type D personality can be assessed with the Type D Scale (DS14) that was originally developed and validated in Belgian cardiac patients [21]. Although its predecessor, the Type D Scale 16 (DS16), was validated in the Danish context [27], new items were included in the DS14 to enhance the assessment of negative affectivity and social inhibition [21]. In addition, the DS14 has advantages over the DS16, as it is a shorter instrument with an easier scoring format. Hence, the DS14 is more suitable to use in clinical and epidemiological research and as a screening instrument in clinical practice to identify high-risk patients.

The aim of the current study was (1) to cross-validate the Danish version of the DS14 in a mixed group of cardiac patients and (2) to examine the impact of Type D personality on symptoms of anxiety and depression. Based on previous research, we expected the Danish DS14 to be a valid and reliable measure to assess Type D personality and that the Type D construct would be significantly correlated with symptoms of anxiety and depression.

\section{Method}

Procedure and Participants

From January 2005 till February 2007, a total of 1,138 patients were approached for participation in the current study, of whom 798 agreed to participate. However, the data quality was only adequate for 726 of these patients. Cases without scores on the DS14 were excluded from statistical analyses $(n=19)$. For all remaining cases, missing data were imputed using the expectation-maximization algorithm, which has been demonstrated to be an effective method of dealing with missing data [24]. Data were not imputed for the Hospital Anxiety and Depression Scale (HADS) and the Eysenck Personality Questionnaire (EPQ) if cases had no scores on these measures. Recruitment was carried out through two channels. The majority of the patients were identified through a database of ischemic heart disease (IHD; $n=464)$ and CHF patients $(n=126)$ at Holbæk Sygehus, Denmark, and the remainder of patients (117 CHF patients) were recruited at CHF outpatient clinics at Aarhus University Hospital (Aarhus Sygehus, Skejby Sygehus, Aalborg Sygehus) and Odense University Hospital. Thus, the final sample consisted of a mixed group of 707 cardiac patients $(n=243$ CHF patients; $n=464$ IHD patients), and time since the cardiac event ranged from 0.5 to 32 years $($ mean $(\mathrm{SD})=4.1 \pm 3.7)$. All questionnaires were filled in at home and returned by post. After 3 or 12 weeks, questionnaires were mailed to all patients of whom only 318 patients responded.

All patients completed the DS14 and the HADS at baseline, whereas only those patients recruited through the outpatient clinics completed the EPQ at baseline $(n=117)$. All patients participating in the follow-up completed the DS14 at either 3 weeks $(n=214)$ or 12 weeks $(n=117)$. Retests were carried out at different time points due to different logistics in relation to the database and the outpatient clinics.

The ethics committee in the municipalities of the participating hospitals approved the study protocol. The study was conducted conform to the Helsinki Declaration, and a returned questionnaire was considered the equivalent of informed consent.

\section{Materials}

\section{Socio-Demographic and Clinical Variables}

Socio-demographic characteristics (age, gender, marital status), and smoking status were based on self-report. Information on clinical characteristics (except smoking status) was obtained from the patients' medical records and included diabetes, hypertension, hypercholesterolemia, 
angina, left ventricular ejection fraction (LVEF), IHD, or CHF, and co-morbidity.

\section{Type D Scale}

The DS14 is a 14-item self-report measure, consisting of two seven-item subscales, negative affectivity (NA; e.g., "I often feel unhappy") and social inhibition (SI; e.g., "I am a closed person") [21]. Responses are indicated on a fivepoint Likert scale from 0 (false) to 4 (true; score range 0-28 for each subscale). A standardized cut-off $\geq 10$ on both subscales indicates Type D caseness [21] with this cut-off being accurate in classifying Type D versus non-Type D [25]. The DS14 has good psychometric properties with Cronbach's $\alpha=0.88 / 0.86$ and 3-month test-retest reliability $r=0.72 / 0.82$ for the negative affectivity and social inhibition subscales, respectively [21]. A recent study of a large sample of AMI patients confirmed the temporal stability of the taxonomy across 18 months and showed that the DS14 is not confounded by disease severity [20].

\section{Eysenck Personality Questionnaire}

The short form of the Eysenck Personality Questionnaire was used to assess neuroticism (12 items) and extroversion (12 items) [26]. These subscales were included to evaluate the convergent validity of the DS14 subscales negative affectivity and social inhibition, as they comprise theoretically similar constructs, yet are not completely overlapping. Hence, the neuroticism and extroversion subscales of the EPQ cannot substitute the negative affectivity and social inhibition subscales of the DS14, as the shared variance has been shown to be below $50 \%$, indicating that, despite overlap in variance, $50 \%$ or more in the Type D subcomponents cannot be explained by the EPQ traits of neuroticism and extroversion [21, 27]. All items are answered with 0 (no) or 1 (yes) (score range 0 12), with a high score indicating more of the personality trait. The validity and reliability of the two subscales have proven satisfactory, with Cronbach's $\alpha$ ranging from 0.80 to 0.87 for the neuroticism subscale and from 0.72 to 0.88 for the extroversion subscale $[26,28]$.

\section{Hospital Anxiety and Depression Scale}

The Hospital Anxiety and Depression Scale is a 14-item self-report measure, consisting of two seven-item subscales that assess anxiety and depressive symptoms devoid of somatic symptoms [29]. Responses to items are indicated on a four-point Likert Scale from 0 to 3 (score range 0-21), with a high score indicating more symptomatology. A cutoff score $\geq 8$ was used for both subscales to identify patients with likely anxiety and depressive symptomatology. This cut-off has been shown to balance sensitivity and specificity optimally [30]. Previous studies have shown that the two HADS subscales are internally consistent, with Cronbach's $\alpha$ for anxiety (HADS-A) $=0.80$ and for depression (HADS$\mathrm{D})=0.81$ [31]. A recent review confirmed the validity and reliability of the HADS across 15 studies, with Cronbach's $\alpha$ for HADS-A ranging from 0.68 to 0.93 and for HADS-D ranging from 0.67 to 0.90 [30].

\section{Statistical Analyses}

Two alternative confirmatory factor models were specified and estimated using LISREL 8.80 [32]. A covariance and asymptotic weight matrix was computed using PRELIS 2.80 [33]. An asymptotic weight matrix allows for weaker assumptions regarding the distribution of observed variables and results in improved fit and test statistics [34, 35]. For the confirmatory factor analysis (CFA), we specified a one-factor model and a two-factor model based on current recommendations (DS14-NA: items number 2, 4, 5, 7, 9, 12, 13; DS-SI: items number $1,3,6,8,10,11,14$ ) [21]. All factors were allowed to correlate, and no correlated errors were included in any of the models. The models were estimated using maximum likelihood, and following the recommendations of Hoyle and Panter [36], we assessed the goodness of fit for each model using a range of fit indices including Satorra-Bentler scaled chi-squared (S-B $\chi^{2}$ ), the incremental fit index (IFI) [37], and the comparative fit index (CFI) [38]. A nonsignificant Satorra-Bentler scaled chi-square and values greater than 0.95 for the IFI and CFI are considered to reflect acceptable model fit. Additionally, the root mean square error of approximation (RMSEA) [39] with $90 \%$ confidence intervals $(90 \%$ CI) are reported, with values less than 0.05 indicating close fit and values up to 0.08 indicating reasonable errors of approximation in the population [40]. The standardized root mean-square residual (SRMR) [41] has been shown to be sensitive to model misspecification and its use is recommended by $\mathrm{Hu}$ and Bentler [42]. Values less than 0.08 are considered to indicate acceptable model fit [43]. The comparative fit of the models was assessed using the expected cross validation index (ECVI) [44], an index used for the purposes of model comparison, with the smallest value indicating the best fitting model. Cronbach's $\alpha$ and the mean inter-item correlation (MIIC) were calculated to determine the internal consistency of the negative affectivity and social inhibition subscales of the DS14. To determine the convergent validity of the DS14 subscales, correlations were calculated between the negative affectivity (DS14-NA) and social inhibition (DS14SI) subscales, EPQ-Extroversion (EPQ-E) and EPQNeuroticism (EPQ-N), HADS-A, and HADS-D. In addition, a principal component analysis based on the six 
subscales was carried out. We used correlations as well as intra-class correlations (ICC) to examine the temporal stability of the Type D construct. To further examine the clinical relevance of the Type D construct in the Danish setting, we stratified the sample by Type D and compared Type D and non-Type D patients on anxiety and depressive symptoms, using multivariable linear regression. In the multivariable analyses, we adjusted for sociodemographic characteristics (age, gender, marital status, and smoking), clinical characteristics (primary diagnosis (CHF vs. AMI), LVEF, angina, hypertension, hypercholesterolaemia, diabetes, and co-morbidity), and anxiety or depression, when the measure in question was not the dependent variable. Secondary analyses, using logistic regression analyses, were performed to investigate the impact of Type D on anxiety or depression diagnosis based on the standardized cut-off $\geq 8$ on the HADS [30]. All analyses were performed using SPSS 13.0 for Windows.

\section{Results}

\section{Baseline Characteristics}

The prevalence of Type D personality was $16 \%$ in the mixed group of cardiac patients, $18.5 \%$ in the CHF patients, and $15 \%$ in the IHD patients. Baseline characteristics stratified by Type D personality are presented in Table 1 . There were no significant differences between Type D and non-Type D patients on socio-demographic and clinical characteristics except for age, with Type D patients being slightly younger.

\section{Confirmatory Factor Analyses}

All fit indices are reported in Table 2. With regard to meeting the criteria associated with the RMSEA, SRMR, CFI, and IFI fit indices, the results indicate the two-factor model to be the better fitting of the models. Although the chi-square test for both models is large relative to degrees of freedom and statistically significant, this should not lead to the rejection of the model, as the large sample size increases the power of the test [45]. The increased power of the chi-square test can result in models with no serious misspecification being rejected, as minor discrepancies between the sample and the implied covariance matrix are detected. In addition, the ECVI also indicates the twofactor model to be a superior solution to the one-factor model. Taken together, this suggests that the theoretically driven two-factor model of the DS14 represents the best description of the current data. The standardized loadings for the two-factor model of the DS14 are presented in Table 3. All factor loadings were statistically significant $(p<0.05)$.

To assess whether our two-factor model was invariant across diagnostic groups, a multi-group analysis was performed. A constrained model with all coefficients set equal across diagnostic groups was compared against an unconstrained model in which all coefficients were allowed to vary across diagnostic groups. The model fitted equally well in both diagnostic groups $\left(\mathrm{S}-\mathrm{B} \chi^{2}(12)=15.18, p=\right.$ 0.23 ), however, when conducting the same analysis assessing invariance of the two-factor model across gender, significant differences emerged (S-B $\chi^{2}(12)=58.21, p<$ 0.01 ), indicating that the two-factor model did not fit equally well across gender.
Table 1 Baseline characteristics stratified by Type D personality

$L V E F$ left ventricular ejection fraction; $\mathrm{CHF}$ chronic heart failure

$*_{p}<0.05$

\begin{tabular}{|c|c|c|c|c|}
\hline & Type $\mathrm{D}(n=115)$ & Non-Type D $(n=592)$ & OR $(95 \% \mathrm{CI})$ & $p$ \\
\hline \multicolumn{5}{|l|}{ Socio-demographic } \\
\hline Age, mean (SD) & $64(10.78)$ & $66(10.28)$ & $0.98(0.96-1.00)$ & $0.03 *$ \\
\hline Males, $n(\%)$ & $84(73)$ & $448(76)$ & $1.16(0.74-1.82)$ & 0.53 \\
\hline Married/co-habiting, $n(\%)$ & $81(73)$ & $442(78)$ & $0.75(0.47-1.20)$ & 0.23 \\
\hline \multicolumn{5}{|l|}{ Clinical } \\
\hline Diabetes, $n(\%)$ & $22(20)$ & $96(17)$ & $1.20(0.72-2.02)$ & 0.48 \\
\hline Hypertension, $n(\%)$ & $49(65)$ & $245(68)$ & $0.84(0.50-1.42)$ & 0.52 \\
\hline Hypercholesterolaemia, $n(\%)$ & $68(80)$ & $331(79)$ & $1.04(0.58-1.86)$ & 0.90 \\
\hline Angina, $n(\%)$ & $86(75)$ & $446(76)$ & $0.96(0.61-1.53)$ & 0.88 \\
\hline LVEF, mean (SD) & $46(17.35)$ & $48(17.34)$ & $1.00(0.98-1.01)$ & 0.42 \\
\hline $\mathrm{CHF}, n(\%)^{2}$ & $45(39)$ & $198(33)$ & $1.28(0.85-1.93)$ & 0.24 \\
\hline Co-morbidity, $n(\%)$ & $43(37)$ & $194(33)$ & $1.20(0.79-1.82)$ & 0.39 \\
\hline Smoking, $n(\%)$ & $29(25)$ & $143(25)$ & $1.05(0.66-1.67)$ & 0.83 \\
\hline
\end{tabular}


Table 2 Confirmatory factor analysis for the DS14

\begin{tabular}{|c|c|c|c|c|c|c|}
\hline Model & S-B $\chi^{2}$, df (p) & RMSEA $90 \%$ CI & ECVI $90 \% \mathrm{CI}$ & IFI & CFI & SRMR \\
\hline Model 1 (1 factor) & $1,620.63,77(<0.001)$ & $0.169(0.16-0.18)$ & $2.37(2.19-2.57)$ & 0.91 & 0.91 & 0.12 \\
\hline Model 2 (2 factors) & $385.45,76(<0.001)$ & $0.076(0.069-0.084)$ & $0.63(0.55-0.72)$ & 0.98 & 0.98 & 0.076 \\
\hline
\end{tabular}

$S-B \chi^{2}$ Satorra-Bentler scaled chi-square, RMSEA root mean square error of approximation, $C I$ confidence intervals, ECVI expected cross validation index, $I F I$ incremental fit index, $C F I$ comparative fit index, SRMR standardized root mean residual

Internal Consistency

Cronbach's $\alpha$ as well as the MIIC was calculated for our two-factor model. MIIC was used because Cronbach's $\alpha$ is highly dependent on the number of items in the scale; hence, the reliability of Cronbach's $\alpha$ as a measure of internal consistency diminishes as the number of scale items increases [46]. In contrast, MIIC indicates the internal consistency of a scale irrespective of the number of items. Cronbach's $\alpha$ for the NA and SI subscales were 0.87 and 0.91 , respectively, and the MIIC for the NA subscale was 0.49 and for the SI subscale 0.59 (Table 2). These coefficients satisfy the criteria for both Cronbach's $\alpha$ and the MIIC [46].

\section{Convergent Validity}

The left side of Table 4 presents the correlation matrix for the DS14, the HADS, and the EPQ subscales. As expected, there were strong associations between DS14-NA and HADS-D and HADS-A as well as with EPQ-N ranging from 0.65 to 0.82 , respectively. These associations account for shared variances ranging between $42 \%$ and $67 \%$, indicating that, although there is considerable overlap between DS14-NA and the other negative affect measures, there is still a considerable amount of unshared variance. There were also strong associations between DS14-SI and HADS-D, HADS-A, and EPQ-N, ranging from -0.33 to -0.52 , indicating a somewhat smaller strength of associa-

Table 3 Standardized factor loadings and internal consistency of the DS14

\begin{tabular}{|c|c|c|c|c|}
\hline \multicolumn{2}{|c|}{ DS14 items } & NA* & $\mathrm{SI}^{*}$ & Internal Consistency* \\
\hline \multicolumn{5}{|c|}{ Negative affectivity } \\
\hline$\# 2$ & I often make a fuss about unimportant things & 0.75 & & 0.59 \\
\hline$\# 4$ & I often feel unhappy & 0.83 & & 0.54 \\
\hline$\# 5$ & I am often irritated & 0.74 & & 0.56 \\
\hline$\# 7$ & I take a gloomy view of things & 0.80 & & 0.71 \\
\hline$\# 9$ & I am often in a bad mood & 0.85 & & 0.75 \\
\hline$\# 12$ & I often find myself worrying about something & 0.84 & & 0.71 \\
\hline \multirow[t]{3}{*}{$\# 13$} & I am often down in the dumps & 0.88 & & 0.70 \\
\hline & & & & $\alpha=0.87$ \\
\hline & & & & $\mathrm{MIIC}=0.49$ \\
\hline \multicolumn{5}{|c|}{ Social inhibition } \\
\hline$\# 1$ & I make contact easily when I meet people ${ }^{a}$ & & 0.66 & 0.68 \\
\hline$\# 3$ & I often talk to strangers ${ }^{\mathrm{a}}$ & & 0.60 & 0.73 \\
\hline \#6 & I often feel inhibited in social interactions & & 0.71 & 0.66 \\
\hline$\# 8$ & I find it hard to start a conversation & & 0.82 & 0.71 \\
\hline$\# 10$ & I am a closed kind of person & & 0.88 & 0.76 \\
\hline$\# 11$ & I would rather keep other people at a distance & & 0.82 & 0.76 \\
\hline \multirow[t]{3}{*}{$\# 14$} & When socializing, I don't find the right things to talk about & & 0.81 & 0.79 \\
\hline & & & & $\alpha=0.91$ \\
\hline & & & & $\mathrm{MIIC}=0.59$ \\
\hline
\end{tabular}

MIIC mean inter-item correlation

${ }^{*} p<0.05$, all factor loadings statistically significant; factor loadings based on confirmatory factor analysis (CFA) for the total sample

${ }^{a}$ Items 1 and 3 uses a reverse scoring format, however scores on these items were reversed prior to conducting the CFA 
tion. Corresponding with the theoretical conceptualization of extroversion, the EPQ-E showed negative correlations with all other scales, most significantly with DS14-SI $(-0.64)$ and least with HADS-A $(-0.33)$. The correlation between DS14-SI and EPQ-E indicates that the shared variance is $41 \%$, again suggesting some, but not complete, overlap between these measures. A principal component analysis of the six subscales showed that DS14-NA in concert with HADS-D, HADS-A, and EPQ-N made up one factor of negative affect, whereas DS14-SI and EPQ-E loaded on a separate factor of inhibition (Table 4, right). Hence, the content of the two separate factors extracted was consistent with the theoretical conceptualization of the Type D construct (Table 4, right). Taken together, the convergent validity of the DS14 was confirmed against scales measuring similar constructs.

\section{Temporal Stability of the Type D Construct}

The temporal stability of the DS14 was examined over a short (3 weeks) and a longer period of time (12 weeks). The mean (SD) score for DS14-NA was 7.23 (5.46) and 7.40 (5.39) for DS14-SI at baseline. Pearson's correlation for NA was $r=0.85$ $(N=214, p<0.01)$ and $r=0.83(N=214, p<.01)$ for $\mathrm{SI}$ between baseline and 3 weeks. Pearson's correlation for NA was $r=0.78(N=117, p<0.01)$ and $r=0.79 \quad(N=117$, $p<.01)$ for SI between baseline and 12 weeks. Intra-class correlation using a two-way mixed effects model, type consistency, and average measures confirmed these results at both 3 weeks (NA $(\mathrm{ICC}=0.92)$; SI $(\mathrm{ICC}=0.91)$ ) and 12 weeks (NA $(\mathrm{ICC}=0.87)$; SI $(\mathrm{ICC}=0.88)$ ). Taken together, these results confirm the temporal stability of the DS14.
Association of Type D with Symptoms of Anxiety and Depression

The prevalence rates of anxiety and depression in Type D and non-Type D patients are depicted in Fig. 1. Univariable linear regression analyses showed that Type D personality was associated with an increased risk of anxiety $(\beta, 0.49$; $p<.001)$ and depression $(\beta, 0.47 ; p<.001)$ as measured by HADS. Logistic regression analysis confirmed these results for both anxiety (odds ratio (OR), 8.92; 95\% CI, 5.74$13.86 ; p<0.001)$ and depression (OR, 9.70; 95\% CI, 5.95$15.82 ; p<0.001)$, with Type $\mathrm{D}$ being associated with a 9 - to 10 -fold increased risk.

In multivariable linear regression analyses, Type D personality remained independently associated with an increased risk of anxiety $(\beta, 0.26 ; p<0.001)$ and depression $(\beta, 0.17 ; p<0.01)$, adjusting for baseline socio-demographic and clinical characteristics and co-occurring mood state (i.e., either anxiety or depressive symptoms). Diabetes and younger age were both independently associated with anxiety and depression, whereas female gender and depressive symptoms were associated with an increased risk of anxiety, and angina and anxiety symptoms were independently associated with depression (results not shown). These results were confirmed in multivariable logistic regression analyses, with Type D being associated with a 4- to 6-fold increased risk of anxiety (OR, 6.81; 95\% CI, 3.26-14.20; $<<0.001)$ and depression (OR, 3.71; 95\% CI, $1.62-8.52 ; p<0.001)$, although younger age was no longer an independent predictor of depression and angina turned out to be a significant predictor of anxiety in these analyses.

Table 4 Correlation matrix and principal component analysis for the subscales of the DS14, HADS and EPQ

\begin{tabular}{|c|c|c|c|c|c|c|c|c|c|}
\hline & & \multicolumn{6}{|c|}{ Correlation Matrix } & \multicolumn{2}{|l|}{ PCA } \\
\hline & & 1 & 2 & 3 & 4 & 5 & 6 & I & II \\
\hline 1 & Social Inhibition (DS14) ${ }^{\mathrm{a}}$ & 1.00 & & & & & & 0.41 & 0.78 \\
\hline 2 & Negative Affectivity (DS14) ${ }^{\mathrm{a}}$ & $0.57 * *$ & 1.00 & & & & & 0.87 & 0.35 \\
\hline 3 & Depression (HADS) $)^{\mathrm{a}}$ & $0.46^{* *}$ & $0.65^{* *}$ & 1.00 & & & & 0.68 & 0.49 \\
\hline 4 & Anxiety (HADS) ${ }^{\mathrm{a}}$ & $0.41 * *$ & $0.76^{* *}$ & $0.66^{* *}$ & 1.00 & & & 0.92 & 0.16 \\
\hline 5 & Neuroticism $(E P Q)^{\mathrm{b}}$ & $0.53 * *$ & $0.82 * *$ & $0.60 * *$ & $0.76^{* *}$ & 1.00 & & 0.87 & 0.27 \\
\hline \multirow[t]{2}{*}{6} & Extroversion $(\mathrm{EPQ})^{\mathrm{b}}$ & $-0.64 * *$ & $-0.44 * *$ & $-0.52 * *$ & $-0.33 *$ & $-0.44 * *$ & 10.00 & -0.16 & -0.92 \\
\hline & Eigenvalues (PCA) & & & & & & & 4.02 & 0.88 \\
\hline
\end{tabular}

$P C A$ Principal component analysis with varimax rotation based on $n=117$

${ }^{*} p<0.05 ;{ }^{*} p<0.01$

${ }^{\text {a }}$ Analysis based on $n=702$

${ }^{\mathrm{b}}$ Analysis based on $n=117$ 


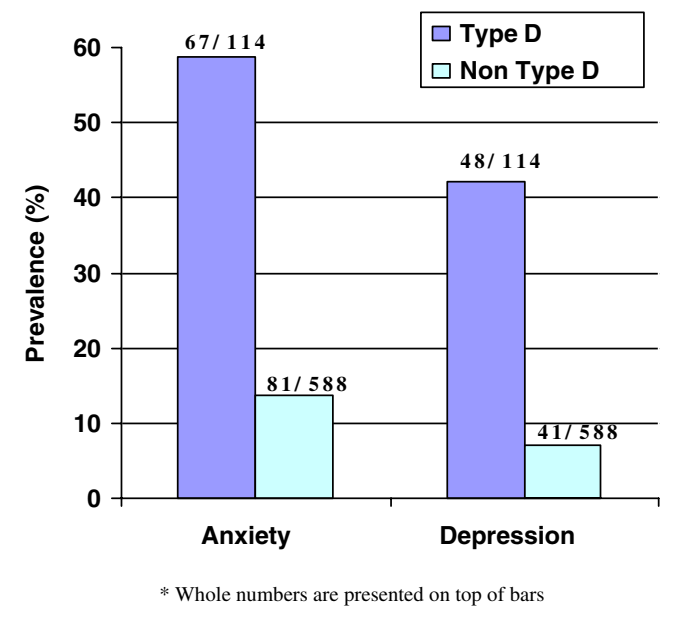

Fig. 1 Prevalence of anxiety and depression in Type D and non-Type D patients*

Does Type D Personality Have Added Value

Above and Beyond Existing Psychological Measures?

To address the question of whether the Type D personality construct merely comprised risk factors for anxiety and depression, we examined whether the addition of Type D personality improved the prediction of a model comprising baseline socio-demographic and clinical characteristics, as well as anxiety or depression, respectively. For this purpose, we ran multivariate logistic stepwise analyses using the enter procedure. The prediction of the model improved significantly with the addition of Type D personality for both anxiety $\left(\chi^{2}=26.85,(d f=1), p<0.01\right)$ and depression $\left(\chi^{2}=9.53,(d f=1), p<0.01\right)$, indicating that the Type $\mathrm{D}$ personality construct has added value above and beyond existing psychological measures.

\section{Discussion}

The current study showed that the Danish version of the Type D Scale (DS14) is a valid and reliable measure of Type D personality in a mixed group of cardiac patients. The two-factor structure was confirmed using confirmatory factor analysis, and the convergent validity was established against scales measuring similar constructs. The Danish DS14 was also shown to be a reliable instrument both in terms of internal consistency and temporal stability over 3 and 12 weeks. Type D personality was an independent associate of both anxiety and depression, adjusting for baseline characteristics and co-occurring mood states, and the prediction of the multivariable model was shown to significantly improve when Type D was added to a model comprising sociodemographic and clinical characteristics. Taken together, these results support the notion that Type D personality incurs an increased risk of mood disorders in cardiac patients.

In the current study, Type $\mathrm{D}$ prevalence rates ranged from $15 \%$ in IHD patients to $18.5 \%$ in CHF patients. These prevalence rates are within the range of those previously published in Type D research [2]. In addition, the conceptualization of NA, as measured by the DS14, was significantly associated with well-established measures of negative affect (i.e., the HADS subscales and EPQ-N), indicating that the DS14-NA items tap relevant aspects of negative affect. We also showed that DS14-SI was significantly associated with a theoretically similar construct, namely EPQ-E. Although statistically there is overlap between these theoretically similar measures, the magnitudes of the shared variance indicate that each measure also contains unique explanatory power. In addition, since Type D caseness is based on personality traits that are considered inherently stable characteristics of the person, the temporal stability of the Type D construct is expected to be good, an assumption which was also confirmed by our results. This assumption was also supported by a recent study of a large sample of postAMI patients over an 18-month period, which also showed that Type D caseness was not confounded by indices of somatic disease [20]. Taken together, the present findings support the use of the Danish DS14 for identifying Type D caseness in cardiac patients.

A recent review on Type D personality presents an upto-date overview of the empirical evidence for the adverse impact of Type D personality on clinical events, health status, and emotional distress, including anxiety, depression, and posttraumatic stress disorder [2]. In the current study, Type D was also found to be an independent associate of anxiety and depression when adjusting for demographic and clinical characteristics. Mood disorders are common in cardiac patients [47-51] and comprise risk factors for morbidity, mortality, and impaired health status $[3,5]$. In addition, there is evidence to suggest that comorbid anxiety and depression may be especially hazardous, since their joint impact on health status has been shown to outweigh that of each factor on their own [9, 10]. In the present study, Type $D$ caseness was associated with more than a 4- to 6-fold increased risk of anxiety and depression, suggesting that this is not just an increase of statistical but also of clinical significance. The current results are in line with previous studies conducted in the Netherlands, showing that Type D personality incurs an increased risk of anxiety and depression [2, 52], including chronic anxiety [53], as well as 12-month onset of depressive symptoms in patients free of depressive symptomatology at 6 months $[9,10]$. In addition, our analysis showed that when controlling for socio-demographic and clinical characteristics known to be associated with both 
anxiety and depression, Type D personality still had unique explanatory power suggesting that the increased risk associated with Type D personality is not just a result of Type D personality comprising all other risk factors for anxiety and/or depression.

Type D personality is an emerging risk factor in CVD [2], and the clinical utility of the construct depends on whether some form of behavioral intervention is available to buffer against the negative impact of Type D on health outcomes. Type D patients are in effect inefficient "copers," as they lack skills to reduce their high levels of emotional distress, in part because they do not turn to their social network for emotional support [54]. Hence, even though it may not be possible to alter the basic personality profile of Type D patients, participation in cardiac rehabilitation focusing on providing new coping skills and strategies may reduce their general levels of distress with potential benefits to health and well-being [55]. In other words, it is likely that Type D patients comprise a subgroup that may require additional intervention compared to non-Type D patients, in order to obtain the same benefits from cardiac rehabilitation and revascularization procedures [56]. For this reason, it is imperative that these high-risk patients can be identified early on, using a brief, valid, and reliable screening instrument such as the DS14.

\section{Limitations}

The results of the current study should be interpreted with some caution. First, we could not reliably estimate the divergent validity of the Danish version of the DS14, which needs to be addressed in future studies. Second, we were not able to reliably carry out a second-order CFA of the three scales used for establishing convergent validity, due to a limited sample size $(n=117)$. Third, we used a self-report measure of anxiety and depression rather than a clinical interview. However, the HADS is a valid and reliable measure of anxiety and depressive symptomatology with good sensitivity and specificity against a clinical diagnostic interview and has been shown to predict mortality in patients referred for exercise testing [57]. An additional advantage of the HADS is that it is not confounded by somatic symptoms. Fourth, due to the cross-sectional design of the study, we cannot infer causation with respect to the impact of Type D on anxiety and depression but only establish that there is an association.

\section{Conclusion}

In conclusion, the Danish DS14 is a valid and reliable instrument for assessing Type D caseness in cardiac patients. Type D personality was associated with a 4- to 6-fold increase in the risk of anxiety and depression, adjusting for demographic and clinical risk factors. The DS14 could be used in research and clinical practice in order to identify high-risk patients, since Type D has been associated with increased distress and adverse health outcomes, including mortality. Studies are now warranted that examine the predictive validity of the DS14 in relation to prognosis in Danish cardiac patients.

Acknowledgments This research was in part supported by the Danish Heart Foundation through grants no. 03-2-9-9-22092 and 064-B505-22283F and by the Netherlands Organisation for Scientific Research (NWO) with a VENI grant (451-05-001) to Dr. SS Pedersen.

Open Access This article is distributed under the terms of the Creative Commons Attribution Noncommercial License which permits any noncommercial use, distribution, and reproduction in any medium, provided the original author(s) and source are credited.

\section{References}

1. Kop WJ, Appels AP, Mendes de Leon CF, de Swart HB, Bar FW. Vital exhaustion predicts new cardiac events after successful coronary angioplasty. Psychosom Med 1994;56:281-7.

2. Pedersen SS, Denollet J. Is type D personality here to stay? Emerging evidence across cardiovascular disease patient groups. Curr Cardiol Rev 2006;2:205-13.

3. Rozanski A, Blumenthal JA, Davidson KW, Saab PG, Kubzansky L. The epidemiology, pathophysiology, and management of psychosocial risk factors in cardiac practice: The emerging field of behavioral cardiology. J Am Coll Cardiol 2005;45:637-51.

4. Clarke SP, Frasure-Smith N, Lesperance F, Bourassa MG. Psychosocial factors as predictors of functional status at 1 year in patients with left ventricular dysfunction. Res Nurs Health 2000;23:290-300.

5. Rumsfeld JS, Havranek E, Masoudi FA, Peterson ED, Jones P, Tooley JF, et al. Depressive symptoms are the strongest predictors of short-term declines in health status in patients with heart failure. J Am Coll Cardiol 2003;42:1811-7.

6. Dimsdale JE. A perspective on type A behavior and coronary disease. N Engl J Med 1988;318:110-12.

7. Denollet J, Van Heck GL. Psychological risk factors in heart disease: what type D personality is (not) about. J Psychosom Res 2001;51:465-8.

8. Lesperance F, Frasure-Smith N. Depression in patients with cardiac disease: A practical review. J Psychosom Res 2000;48:379-91.

9. Pedersen SS, Denollet J, Spindler H, Ong AT, Serruys PW, Erdman RA, et al. Anxiety enhances the detrimental effect of depressive symptoms on health status following percutaneous coronary intervention. J Psychosom Res 2006;61:783-9.

10. Pedersen SS, Ong AT, Sonnenschein K, Serruys PW, Erdman RA, van Domburg RT. Type D personality and diabetes predict the onset of depressive symptoms in patients after percutaneous coronary intervention. Am Heart J 2006;151:367.e1-367.e6.

11. Sullivan MD, LaCroix AZ, Spertus JA, Hecht J. Five-year prospective study of the effects of anxiety and depression in patients with coronary artery disease. Am J Cardiol 2000;86:1135-8, A6, A9.

12. Carney RM, Freedland KE, Eisen SA, Rich MW, Jaffe AS. Major depression and medication adherence in elderly patients with coronary artery disease. Health Psychol 1995;14:88-90. 
13. DiMatteo MR, Lepper HS, Croghan TW. Depression is a risk factor for noncompliance with medical treatment: Meta-analysis of the effects of anxiety and depression on patient adherence. Arch Intern Med 2000;160:2101-7.

14. Frasure-Smith N, Lesperance F, Gravel G, Masson A, Juneau M, Talajic M, et al. Depression and health-care costs during the first year following myocardial infarction. J Psychosom Res 2000;48:471-8.

15. Sullivan M, Simon G, Spertus J, Russo J. Depression-related costs in heart failure care. Arch Intern Med 2002;162:1860-6.

16. Nicholson A, Kuper H, Hemingway H. Depression as an aetiologic and prognostic factor in coronary heart disease: A meta-analysis of 6362 events among 146538 participants in 54 observational studies. Eur Heart J 2006;27:2763-74.

17. Denollet J, Pedersen SS, Ong AT, Erdman RA, Serruys PW, van Domburg RT. Social inhibition modulates the effect of negative emotions on cardiac prognosis following percutaneous coronary intervention in the drug-eluting stent era. Eur Heart J 2006;27:171-7.

18. Pedersen SS, van Domburg RT, Theuns DA, Jordaens L, Erdman RA. Type D personality is associated with increased anxiety and depressive symptoms in patients with an implantable cardioverter defibrillator and their partners. Psychosom Med 2004;66:714-9.

19. De Jonge P, Denollet J, Van Melle JP, Kuyper A, Honig A, Schene $\mathrm{AH}$, et al. Associations of type-D personality and depression with somatic health in myocardial infarction patients. J Psychosom Res 2007;63:477-82.

20. Martens EJ, Kupper N, Pedersen SS, Aquarius AE, Denollet J. Type-D personality is a stable taxonomy in post-MI patient over an 18-months period. J Psychosom Res 2007;63:545-50.

21. Denollet J. DS14: Standard assessment of negative affectivity, social inhibition, and type D personality. Psychosom Med 2005;67:89-97.

22. Whitehead DL, Perkins-Porras L, Strike PC, Magid K, Steptoe A. Cortisol awakening response is elevated in acute coronary syndrome patients with type-D personality. J Psychosom Res 2007;62:419-25.

23. Denollet J, Vaes J, Brutsaert DL. Inadequate response to treatment in coronary heart disease: Adverse effects of type D personality and younger age on 5-year prognosis and quality of life. Circulation 2000;102:630-5.

24. Bunting BP, Adamson G, Mulhall P. A monte carlo examination of MTMM model with planned incomplete data structures. Struct Equ Modeling 2002;9:369-89.

25. Emons WH, Meijer RR, Denollet J. Negative affectivity and social inhibition in cardiovascular disease: Evaluating type-D personality and its assessment using item response theory. J Psychosom Res 2007;63:27-39.

26. Eysenck SB, Eysenck HJ, Barrett P. A revised version of the psychoticism scale. Pers Individ Differ 1985;6:21-9.

27. Pedersen SS, Denollet J. Validity of the type D personality construct in Danish post-MI patients and healthy controls. J Psychosom Res 2004;57:265-72.

28. Sanderman R, Arindell WA, Ranchor AV, Eysenck HJ, Eysenck SB. Eysenck personality questionnaire: Een handleiding (Eysenck Personality Questionnaire: Manual). Groningen: Regenboog; 1995.

29. Zigmond AS, Snaith RP. The hospital anxiety and depression scale. Acta Psychiatr Scand 1983;67:361-70.

30. Bjelland I, Dahl AA, Haug TT, Neckelmann D. The validity of the hospital anxiety and depression scale. an updated literature review. J Psychosom Res 2002;52:69-77.

31. Herrmann C. International experiences with the hospital anxiety and depression scale-a review of validation data and clinical results. J Psychosom Res 1997;42:17-41.
32. Jöreskog K, Sörbom D. LISREL 8.80. Chicago: Scientific Software International, Inc.; 2006.

33. Jöreskog K, Sörbom D. PRELIS 2.80. Chicago: Scientific Software International, Inc.; 2006.

34. Curran PJ, West SG, Finch JF. The robustness of test statistics to nonnormality and specification error in confirmatory factor analysis. Psychol Methods 1996;1:16-29.

35. Satorra A. Asymptotic robust inferences in the analysis of mean and covariance structures. Sociol Method 1992;22:249514.

36. Hoyle RH, Panter AT. Writing about structural equation models. In: Hoyle RH, editor. Structural equation modeling: Concepts, issues, and applications. Thousand Oaks, CA, US: Sage Publications, Inc.; 1995. p. 158-76.

37. Bollen KA. Structural equations with latent variables. Oxford, England: Wiley; 1989.

38. Bentler PM. Comparative fit indexes in structural models. Psychol Bull 1990;107:238-238.

39. Steiger JH. Structural model evaluation and modification: An interval estimation approach. Multivariate Behav Res 1990;25:173-173.

40. Jöreskog K, Sörbom D. Structural equation modeling with the SIMPLIS command language. Chicago: Scientific Software; 1993.

41. Jöreskog K, Sörbom D. LISREL V: Analysis of linear structural relationships by the method of maximum likelihood. . Chicago: National Educational Resources; 1981.

42. $\mathrm{Hu} \mathrm{L}$, Bentler PM. Cutoff criteria for fit indexes in covariance structure analysis: Conventional criteria versus new alternatives. Struct Equ Modeling 1999;6:1-1.

43. $\mathrm{Hu} \mathrm{L}$, Bentler PM. Fit indices in covariance structure modeling: Sensitivity to underparameterized model misspecification. Psychol Methods 1998;3:424-424.

44. Browne MW, Cudeck R. Single sample cross-validation indices for covariance structures. Multivariate Behav Res 1989;24:445445.

45. Tanaka JS. "How big is big enough?": sample size and goodness of fit in structural equation models with latent variables. Child Dev 1987;58:134-134.

46. Briggs SR, Cheek JM. The role of factor analysis in the development and evaluation of personality scales. J Person. Special Issue: Methodol Dev Person Res 1986;54:106-48.

47. Frasure-Smith N, Lesperance F. Reflections on depression as a cardiac risk factor. Psychosom Med 2005;67:S19-25.

48. Grace SL, Abbey SE, Irvine J, Shnek ZM, Stewart DE. Prospective examination of anxiety persistence and its relationship to cardiac symptoms and recurrent cardiac events. Psychother Psychosom 2004;73:344-52.

49. Januzzi JL Jr, Stern TA, Pasternak RC, DeSanctis RW. The influence of anxiety and depression on outcomes of patients with coronary artery disease. Arch Intern Med 2000; 160:1913-21.

50. Kubzansky LD, Davidson KW, Rozanski A. The clinical impact of negative psychological states: Expanding the spectrum of risk for coronary artery disease. Psychosom Med 2005;67:S10-4.

51. Spindler H, Pedersen SS. Posttraumatic stress disorder in the wake of heart disease: Prevalence, risk factors, and future research directions. Psychosom Med 2005;67:715-23.

52. van Gestel YR, Pedersen SS, van de Sande M, de Jaegere PP, Serruys PW, Erdman RA, et al. Type-D personality and depressive symptoms predict anxiety 12 months post-percutaneous coronary intervention. J Affect Disord 2007;103:197-203.

53. Spindler H, Pedersen SS, Serruys PW, Erdman RA, van Domburg RT. Type-D personality predicts chronic anxiety following percutaneous coronary intervention in the drug-eluting stent era. J Affect Disord 2007;99:173-9. 
54. Doering LV, Dracup K, Caldwell MA, Moser DK, Erickson VS, Fonarow $\mathrm{G}$, et al. Is coping style linked to emotional states in heart failure patients? J Card Fail 2004;10:344-9.

55. Denollet J, Brutsaert DL. Reducing emotional distress improves prognosis in coronary heart disease: 9 -year mortality in a clinical trial of rehabilitation. Circulation 2001;104:2018-23.
56. Pedersen SS, Denollet J, Ong AT, Serruys PW, Erdman RA, van Domburg RT. Impaired health status in type D patients following PCI in the drug-eluting stent era. Int J Cardiol 2007;114:358-65.

57. Herrmann C, Brand-Driehorst S, Buss U, Ruger U. Effects of anxiety and depression on 5-year mortality in 5,057 patients referred for exercise testing. J Psychosom Res 2000;48:455-62. 